\title{
EL ARBITRAJE EN EL ANTEPROYECTO DE CÓDIGO MERCANTIL ${ }^{1}$
}

MANUEL OLIVENCIA RUIZ

Catedrático Emérito de Derecho Mercantil de la Universidad de Sevilla

Vicepresidente de Cuatrecasas, Gonçalves-Pereira

RESUMEN: El pasado 30 de mayo se aprobó en Consejo de Ministros el Anteproyecto de Código Mercantil (ACM). La Sección 2a de la CGC aborda el tema del arbitraje societario, que este trabajo quiere analizar.

PALABRAS CLAVE: Arbitraje societario, Código Mercantil

ABSTRACT: On 30 May, it was approved by the Cabinet the Draft Commercial Code (ACM). The CGC Section 2 addresses the issue of corporate arbitration, this work wants to analyze.

KEYWORDS: Commercial code, arbitration

Sumario.- I. Elección del tema.- II. El arbitraje estatutario en la Ley 11/2011, de Reforma de la Ley de Arbitraje. 1. Las nuevas normas; 2. Mi crítica; 3. Mis apoyos; a) Doctrina científica; b) Doctrina del Tribunal Constitucional; c) Tribunal Supremo; d) Derecho comparado.- III. El arbitraje estatutario en la Propuesta de Código Mercantil. 1. Las normas propuestas. 2. La cláusula estatutaria de arbitraje; a) Ubicación y contenido; b) Diferencias con la Ley vigente; c) La inspiración italiana y las diferencias. 3. La exclusión de las sociedades cotizadas.- IV. La inscripción en el Registro Mercantil del laudo estimatorio de la impugnación de acuerdo inscrito.

\footnotetext{
${ }^{1}$ Este trabajo se trata de la conferencia pronunciada en el Curso de Verano "El arbitraje civil y mercantil" celebrado en Almería en julio de 2014
} 


\section{ELECCIÓN DEL TEMA}

Ante todo, mi agradecimiento a los organizadores de este Curso y a su Director, especialmente, por haberme honrado con la invitación a participar en él y reservado el privilegio de pronunciar la conferencia de clausura, que no será el "broche de oro", sino simplemente el broche de un "curso de oro".

He querido corresponder a tanto honor con un tema de actualidad y de interés. La actualidad la tiene, indudablemente, el Anteproyecto de Código Mercantil (ACM) aprobado en Consejo de Ministros el 30 de mayo pasado, día de San Fernando. Señalo la onomástica por la coincidencia cronológica con la fecha de promulgación de nuestro primero C. de c., obra del insigne jurista andaluz D. PEDRO SÁINZ DE ANDINO: 30 de mayo de 1829. Fue un regalo que en el día de su Santo se hizo al Rey Fernando VII, quien lo agradeció con su firma de promulgación.

Ahora, 185 años después de nuestro primer C. de c. de 1829, y cuando se van a cumplir 129 años del vigente, de 1885, se anuncia el nuevo Código Mercantil del siglo XXI, cuya elaboración encargó el Ministro de Justicia del primer gobierno de D. JOSÉ LUIS RODRÍGUEZ ZAPATERO, DON JUAN FERNANDO LÓPEZ AGUILAR, a la Sección 2a , de Derecho Mercantil, de la Comisión General de Codificación, mediante OMJ de 7 de noviembre de 2006.

Tras siete años de trabajo (tres más del plazo señalado por el Ministro), el 17 de junio de 2013 el Presidente de la Sección 2a de la CGC, Prof. ALBERTO BERCOVITZ, entregó a D. ALBERTO RUIZ GALLARDÓN, Ministro de Justicia del gobierno 
presidido por D. MARIANO RAJOY, la Propuesta de Código Mercantil ${ }^{2}$ y, tras su estudio por los departamentos ministeriales, el Gobierno la hizo "Anteproyecto" en el señalado día de San Fernando, Rey.

Actualidad tiene todo lo que se refiera al ACM; pero me temo que pierda interés el tema elegido si comienzo por decir que el ACM no regula el arbitraje. No lo hace por una razón bien sencilla: el ACM tiene como "ámbito objetivo" los actos y contratos "mercantiles", y el arbitraje no dimana hoy en nuestro Derecho de un contrato "mercantil". El convenio arbitral es civil, por naturaleza, aunque la regulación del arbitraje tenga su origen en normas "mercantiles", "sobre arbitraje comercial internacional", como es el ámbito propio de la Ley Modelo de UNCITRAL, de 21 de junio de 1985, así llamada, en la que se inspira la Ley de Arbitraje española (LA) de 2003.

De la misma forma que nuestro sistema es "monista", porque regula el arbitraje interno y el internacional, lo es también porque regula el civil y el mercantil, con lo que se convierte en "común". Sus principios inspiradores serán de origen "mercantil”, pero pierden esta calificación al convertirse en "comunes". No existe en España un arbitraje mercantil diverso del civil; no existe una regulación separada de estas dos figuras.

Sólo durante el siglo XIX, de 1830 a 1868, rigió una regulación especial del arbitraje mercantil. Me refiero a la contenida en la llamada Ley de Enjuiciamiento sobre los negocios y causas de comercio, de 24 de julio de 1830, anunciada por el Código de comercio de 1829 en su último artículo, el 1.219, del mismo autor y "sancionada y promulgada" por el mismo Rey, que regulaba el juicio de árbitros y el de amigables componedores en su Título VI (arts. 252-304). El art. 252 disponía que "Toda contienda sobre negocios mercantiles puede ser comprometida al juicio de árbitros de comercio...", y el 296, que "Los comerciantes podrán también comprometer la decisión de sus contiendas en amigables componedores que decidan sobre ellas sin sujeción a las formas legales, según su leal saber y entender".

\footnotetext{
${ }^{2}$ Propuesta de Código Mercantil elaborada por la Sección de Derecho Mercantil de la Comisión General de Codificación, Ministerio de Justicia, Madrid, 2013.
} 
A partir de 1 de enero de 1856, bajo el reinado de Isabel II, el arbitraje mercantil convivió con la LEC promulgada en 5 de octubre de 1855, que entró en vigor con aquella fecha y cuyos Títulos XV y XVI de su Parte Primera, "Jurisdicción contenciosa", regulaban, respectivamente, el juicio arbitral (arts. 770-818) y el de amigables componedores (arts. 819-836), en el orden civil, con normas muy distintas de las de la Ley de 1830 para el orden mercantil, una regulación más imperativa, rigurosa, formalista y lenta que la diseñada por D. PEDRO SÁINZ DE ANDINO, caracterizada por su mayor autonomía de la voluntad, flexibilidad y rapidez, como adecuada a las exigencias del comercio.

La "coexistencia" duró hasta que el Decreto de "refundición de fueros", de 8 de diciembre de 1868, fruto temprano de la Revolución liberal septembrina ("la Gloriosa") no sólo abolió la jurisdicción especial de comercio que el C. de c. de 1829 regulaba en su Libro V, "De la administración de justicia en los negocios de comercio", sino que derogó la Ley de Enjuiciamiento sobre los negocios y causas de comercio de 1830 y, con ella, el arbitraje mercantil. Es lo que he llamado "Una contradicción de los liberales de 1868: la regulación del arbitraje"3, porque, con su obsesión anticlasista, suprimieron un procedimiento que no era privilegio de clase, como la jurisdicción, sino adecuado a las exigencias objetivas de la actividad mercantil, que requiere más rapidez en la tramitación, mayor autonomía de la voluntad y menos formalismos que la civil.

Los revolucionarios se dieron cuenta pronto del despropósito de derogar la regulación más "liberal" del arbitraje mercantil, cuando en el Decreto de 2 de septiembre de 1869 anunciaron un Código de Enjuiciamiento comercial, que regularía los procedimientos de esta naturaleza (incluido el de arbitraje), de "métodos más rápidos y expeditos" que los civiles ${ }^{4}$. Pero el propósito quedó en anuncio y no hubo nunca más regulación del arbitraje que la civil, contenida en las Leyes de EC de 1855 y

\footnotetext{
${ }^{3}$ Es el título de mi ponencia a la Real Academia de Jurisprudencia y Legislación, de 19 de enero de 2009; v. en ANALES, n 39, Madrid, 2009, pp. 157-175.
}

\footnotetext{
${ }^{4}$ V. mi ponencia "Derecho mercantil y proceso", presentada a la Real Academia de Jurisprudencia y Legislación en 18 de enero de 2010, en ESTUDIOS, Madrid, 2010, pp. 196-206.
} 
1881 y, a partir de la Ley de 23 de diciembre de 1953, en las especiales 36/1988, de 5 de diciembre, y 60/2003, de 23 de diciembre, vigente.

Esta última, responde a la finalidad, advertida en la E. de M (I), de atemperar la regulación del arbitraje a la evolución del tráfico jurídico, "sobre todo en su vertiente comercial internacional", aunque la regulación sea "unitaria" para todo arbitraje, comercial o civil, interno o internacional.

Por eso, los redactores del nuevo CM nos encontramos con un modelo de arbitraje que lo excluía del texto propuesto; pero nos hallamos también ante una reforma parcial de la LA de 2003, la introducida en su texto por la Ley 11/2011, de 20 de mayo, que aborda una materia mercantil, como es el arbitraje estatutario en las sociedades de capital, añadiendo al texto originario dos nuevos artículos, numerados como arts. 11 bis y 11 ter.

Son estas nuevas normas las que obligaron a los redactores de la PCM a reconsiderar el tema.

\section{EL ARBITRAJE ESTATUTARIO EN LA LEY 11/2011, DE REFORMA DE LA LEY DE ARBITRAJE}

\section{Las nuevas normas}

El texto de estos artículos es el siguiente:

“Artículo 11 bis. Arbitraje estatutario.

1. Las sociedades de capital podrán someter a arbitraje los conflictos que en ellas se planteen.

2. La introducción en los estatutos sociales de una cláusula de sumisión a arbitraje requerirá el voto favorable de, al menos, dos tercios de los votos correspondientes a las acciones o a las participaciones en que se divida el capital social. 
3. Los estatutos sociales podrán establecer que la impugnación de los acuerdos sociales por los socios o administradores quede sometida a la decisión de uno o varios árbitros, encomendándose la administración del arbitraje y la designación de los árbitros a una institución arbitral.

Artículo 11 ter. Anulación por laudo de acuerdos societarios inscribibles.

1. El laudo que declare la nulidad de un acuerdo inscribible habrá de inscribirse en el Registro Mercantil. El 'Boletín Oficial del Registro Mercantil' publicará un extracto.

2. En el caso de que el acuerdo impugnado estuviese inscrito en el Registro Mercantil, el laudo determinará, además, la cancelación de su inscripción, así como la de los asientos posteriores que resulten contradictorios con ella".

\section{Mi crítica}

He sido muy crítico con la reforma de la Ley 11/2011, en general, y con la relativa al arbitraje societario en especial ${ }^{5}$. La he tachado de "inoportuna" y de

\footnotetext{
${ }^{5}$ V. una crítica general en mi trabajo "El arbitraje en España. Impacto de la Ley 11/2011, de Reforma de la Ley 60/2003", en RJC, n 4, 2012, pp. 128-152. En especial, sobre el arbitraje societario, v. además, mi comentario al Artículo 11 bis LA en Comentarios a la nueva Ley de Arbitraje, coord. GONZÁLEZ SORIA, J., $2^{\mathrm{a}}$ ed., Cizur Menor, 2011, pp. 169 y ss., especialmente, pp. 175-176; "Company Arbitration in Spanish Law", en Homenaje al Prof. José M ${ }^{a}$ Abascal, World Arbitration \& Mediation Review, vol. 6, $\mathrm{n}^{\mathrm{o}}$ 2, 2012, pp. 369-384; "La cláusula de arbitraje introducida por vía de modificación de los estatutos sociales", en Actas del XI Congreso de la Asociación Sainz de Andino. Homenaje al Prof. Juan Manuel Gómez Porrúa, Madrid, 2012, pp. 11-20; Discurso de contestación al de ingreso de CARMEN MOYA SANABRIA en la Real Academia Sevillana de Legislación y Jurisprudencia: Evolución histórica y estudio de la voluntad como fundamento de la institución arbitral. Capacidad y legitimación de las partes, Sevilla, 2011, pp. 75-79; Ponencia en la Real Academia de Jurisprudencia y Legislación: "Cláusula estatutaria de arbitraje impuesta por acuerdo mayoritario en las sociedades de capital (art. 11 bis.2 de la Ley de Arbitraje)", en Estudios, 2012 (en prensa); "El arbitraje y la Constitución de 1812", acto conmemorativo del CC aniversario de ésta organizado por la CIMA, Madrid, mayo 2012; "Las aportaciones del Prof. Vicent Chuliá al arbitraje societario", en Estudios de Derecho Mercantil. Liber Amicorum Profesor Dr. Francisco Vicent Chuliá; Valencia, 2013, pp. 491-498; "Quórum y mayorías en las sociedades de capital. A propósito del artículo 11 bis.2 de la Ley de Arbitraje", en Liber Amicorum al Prof. Juan Luis Iglesias, Madrid, 2014, pp. 799-817; Ponencia en el XII Congreso de la Asociación Andaluza de Profesores de Derecho Mercantil PEDRO SAINZ DE ANDINO: "Constitución y Arbitraje", Cádiz, 2012 (en prensa).
} 
"innecesaria" y he censurado, concretamente, la relativa al arbitraje societario (arts. 11 bis y 11 ter) como la "más importante y, al mismo tiempo, más desafortunada".

Mis críticas se dirigían contra los siguientes defectos de la reforma:

$1^{\circ}$. Referirse expresamente sólo a las sociedades de capital, y no a las de personas.

$2^{\circ}$. No distinguir entre el arbitraje estatutario y el común, pactado mediante convenio arbitral extra-estatutario.

$3^{\circ}$. No contemplar expresamente el arbitraje societario introducido en los estatutos fundacionales, sino solo el introducido por acuerdo de modificación de los estatutos.

$4^{\circ}$ No aclarar si el arbitraje ha de ser de Derecho o puede ser de equidad.

$5^{\circ}$. Enmendar el Proyecto de Ley presentado por el Gobierno, que exigía "el acuerdo de todos los socios", en el sentido de admitir la mayoría cualificada de dos tercios de los votos correspondientes a las acciones o a las participaciones en que se divida el capital social.

Es este último punto, sin duda, el más grave. Mientras los anteriores se deben a defectos de redacción o de técnica legislativa, subsanables por la vía de una correcta interpretación de las normas, la imposición del arbitraje por mayoría, aunque sea cualificada, vulnera, a mi juicio, el derecho a la tutela judicial efectiva del art. $24 \mathrm{CE}, \mathrm{y}$ destruye la base sobre la que se fundamenta en ésta la institución arbitral: la libertad, como valor superior de nuestro Ordenamiento jurídico (art. $1^{\circ} \mathrm{CE}$ ).

También he expuesto mi crítica en foros como el III Congreso de Instituciones Arbitrales: La reforma de la Ley de Arbitraje, organizado por la Corte de Arbitraje de Madrid de la Cámara de Comercio, 2011; la Jornada sobre Arbitraje y Mediación. Métodos alternativos eficaces para la resolución de conflictos, organizado por CUATRECASAS, GONÇALVES PEREIRA, OLIVENCIA-BALLESTER, en el Instituto de Estudios Cajasol, el 16 de marzo de 2012, y el IX Curso de Arbitraje de la Universidad Rey Juan Carlos, 11 de febrero de 2014. 
La exigencia de unanimidad, que ya tenía precedente en la Propuesta de Código de Sociedades Mercantiles, era consecuencia obligada de ese principio de libertad y se cambió en el Congreso de los Diputados por la de mayoría cualificada en virtud de enmiendas (del Grupo Catalán, fundamentalmente), sometidas a un debate ligero e inconsciente, porque de su lectura se desprende que los parlamentarios no se apercibieron de la verdadera entidad del problema, ni, por tanto, entraron, en su fondo. Su intención fue solo la de impulsar la difusión del arbitraje, facilitando su inclusión en los estatutos sociales. No se dieron cuenta de que esa difusión se hacía a expensas de la esencia misma del arbitraje, que es, desde la Constitución de Cádiz de 1812, el “incontrastable principio de la libertad”. Lo sacrificaron al imponer el arbitraje a la minoría disidente o ausente (no votante del acuerdo) y al prohibir a ésta, consecuentemente, el acceso a la vía judicial y al juez natural.

\section{Mis apoyos}

Mi severa crítica a la regulación del arbitraje estatutario por la reforma de 2011 iba bien arropada.

\section{a) Doctrina científica}

En la doctrina científica española, se apoyaba en las autorizadas opiniones de MUÑOZ PLANAS, J.M ${ }^{\mathrm{a}}$; POLO, E. ; VICENT CHULIÁ, F. ${ }^{8}$, y GÓMEZ PORRÚA, J.M. .

\footnotetext{
6 "Algunos problemas del arbitraje en materia de sociedades mercantiles", en Estudios de Derecho Mercantil en homenaje a RODRIGO URÍA, Madrid, 1978, pp. 381-498. Me declaré "corifeo" de esta doctrina en mi nota necrológica a «José María Muñoz Panas. "In memoriam"», en RDM, nº 283, 2012, pp. 17-21, especialmente pp. 19-20. V. también, en coatoria con José M M MUÑOZ PAREDES, "La impugnación de acuerdos de la Junta general mediante arbitraje", en Estudios en homenaje al Prof. Fernando Sánchez Calero, II, Madrid, 2002, pp. 1977-2029.
}

\footnotetext{
7 "Introducción y ámbito de eficacia de la cláusula compromisoria en las sociedades mercantiles", en Tribunal Arbitral de Barcelona, Seminario sobre Arbitraje en las Sociedades mercantiles, $\mathrm{n}^{\circ} 4$, Barcelona, 1992, pp. 64-100.
} 
b) Doctrina del Tribunal Constitucional

En la doctrina constitucional, no sólo se apoyaba en las reiteradas Sentencias del TC que basan el arbitraje en la autonomía de la voluntad y lo anclan, en última instancia, en la libertad, como valor superior del Ordenamiento jurídico ${ }^{10}$, sino en una Sentencia específica, del Pleno ${ }^{11}$, la $n^{\circ}$ 174/1995, de 23 de noviembre, Ponente FERNANDO GARCÍA MON, que establece con claridad que "la autonomía de la voluntad de las partes - de todas las partes- constituye la esencia y el fundamento de la institución arbitral y "por tanto, resulta contrario a la CE que la Ley suprima o prescinda de la voluntad de una de las partes para someter la contraria al arbitraje...”.

Sobre esos fundamentos, se declaró la inconstitucionalidad de la norma de la LOTT que establecía el arbitraje obligatorio, a no ser que las partes hubiesen pactado acudir a la vía judicial. Y es lógico que lo que no puede imponer una ley no lo pueda hacer un acuerdo de la junta general de una sociedad de capital.

${ }^{8}$ Compendio de Derecho Mercantil, I-1 ${ }^{\circ}, 3^{\text {a }}$ ed., Barcelona 1991, pp. 616 y ss. V. también mi artículo "Las aportaciones del Prof. Vicent Chuliá al arbitraje societario", op. et loc. cit.

9 "La cláusula compromisoria estatutaria y su aplicabilidad a la impugnación de acuerdos sociales en las sociedades de capital", en Derecho de Sociedades. Libro Homenaje al Profesor FERNANDO SÁNCHEZ CALERO, vol. II, Madrid, 2002, pp. 1925-1975. V. también mi artículo "La cláusula de arbitraje introducida por vía de modificación de los estatutos sociales", op. et loc. cit.

${ }^{10}$ V. SSTC, Sala primera, no 75/1996, de 30 de abril, ponente PEDRO CRUZ VILLALÓN; Sala Segunda, $\mathrm{n}^{\circ}$ 176/1996, de 11 de noviembre, ponente JULIO DIEGO GONZÁLEZ CAMPOS; Sala Primera, $\mathrm{n}^{\circ}$ 9/2005, de 17 de enero, ponente FRANCISCO JAVIER DELGADO BARRIO; del Pleno, n 352/2006, de 14 de diciembre, del mismo ponente, entre otras; vid. CRUZ VILLALÓN, P., "Arbitraje y Constitución en España”, en La Ciencia del Derecho Procesal Constitucional. Estudios homenaje a HÉCTOR FIX-ZAMUDIO, XI, México, 2008, pp. 421-435, especialmente p. 432.

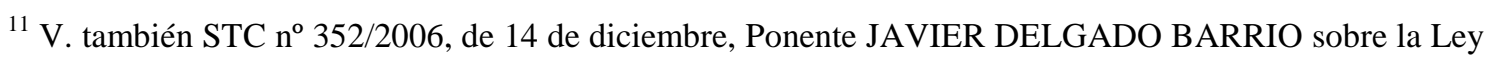
de Ordenación del Transporte Terrestre (LOTC). 


\section{c) Tribunal Supremo}

Mi opinión crítica seguía la línea marcada por la STS de la Sala 1a , de 9 de julio de 2007, ponente JOSÉ A. XIOL RIOS. Esta esmerada Sentencia relaciona los requisitos del convenio arbitral ex art. 5 LA de 1988 (exigencia de expresión de la "voluntad inequívoca" de someter la solución de los litigios a la decisión arbitral) con el principio de autonomía de la voluntad en que funda la doctrina constitucional la institución del arbitraje (STC 9/2005), para concluir que "el arbitraje supone una renuncia a la intervención de los tribunales" y, en consecuencia, "la modificación de los estatutos de una sociedad que comporte una sumisión a arbitraje para la resolución de los conflictos sociales o una ampliación de su ámbito objetivo, en cuanto comporta una forma de restricción o limitación del derecho a la tutela judicial efectiva que puede hacerse valer por la vía del amparo, según la jurisprudencia constitucional... exige el requisito de la aceptación de los afectados".

\section{d) Derecho comparado}

En el Derecho comparado, mi modelo era el sistema germánico, en el que, aun no existiendo norma expresa sobre el tema, es pacífica la interpretación doctrinal y jurisprudencial en el sentido de que para incorporar una cláusula de arbitraje mediante un acuerdo de modificación de estatutos ha de adoptarse por todos los socios, por respeto al art. 101.1 de la Grundgesetz (la Constitución) en materia de tutela judicial o por afectar a derechos del socio ${ }^{12}$.

\footnotetext{
${ }^{12}$ V. EMMERICH, V., en SCHOLZ, GmbH Gesetz, Köln, 1993, p. 542; LUTTER-HOMMELHOFF, GmbH-Gesetz, $17^{\mathrm{a}}$ ed., Köln, 2009, p. 1157, § 47.98. En la doctrina austríaca, ZÖHLNER, ROTH, ULMER/RAISER, RAESCHKE-KESSLER/WIEGAND, REICHERT/HARBARH, SCHNEIDER, STRAUSSE, REUTER-MICHRAHM, GmbH. Wiener Kommentar, Wien, 2010, pp. 33, § 4.40; 49.125; § 50.4 .
} 
Y ello, sólo respecto de la s.r.l., porque en la s.a. (art. 23.5 AktGesetz) no se prevé la cláusula de arbitraje entre las que pueden pactarse en los estatutos sociales. Como se sabe, la Ley alemana de s.a. no permite más pactos estatutarios que los expresamente autorizados en ella, y el de arbitraje no se contempla.

Por bien abrigada que estuviera mi opinión, favorable al arbitraje societario en los estatutos fundacionales pero absolutamente contraria a su introducción posterior por vía de acuerdo mayoritaria de modificación de estatutos, incluso con la mayoría cualificada de los $2 / 3$ de los votos, lo cierto es que quedó en "franca minoría" mi defensa de la minoría frente a la imposición de la mayoría. Conté con la compañía, siempre reconfortante, de VICENT CHULIÁ ${ }^{13}$, pero la mayoría de la doctrina, especialmente la militante en los medios profesionales del arbitraje, acogió con entusiasmo la solución “pragmática” y “útil” de la reforma española14.

\section{EL ARBITRAJE ESTATUTARIO EN LA PROPUESTA DE CÓDIGO MERCANTIL}

\section{Las normas propuestas.}

Ante ese panorama se encontró la Sección $2^{\mathrm{a}}$ de la CGC al abordar el tema del arbitraje societario, con la circunstancia de que en su seno se hallaban presentes defensores de las dos posiciones antagónicas ${ }^{15}$.

\footnotetext{
${ }^{13}$ V. VICENT CHULIÁ, F., Introducción al Derecho Mercantil, I, 23ª ed., Valencia, 2012, pp. 738 y ss.; v. también mi trabajo "Las aportaciones...", cit., pp.491-498.
}

${ }^{14}$ V. el Informe sobre el arbitraje societario en España, del Club Español del Arbitraje, Madrid, 2013, especialmente, pp. 34 a 37.

${ }^{15}$ Destaco como defensores del principio de mayoría en la introducción de la cláusula, a los Vocales Profesores ILLESCAS, RAFAEL, y GALLEGO, ESPERANZA. La tesis de la unanimidad la mantuve yo. 
Frente a tan reciente como defectuosa reforma y la polémica por ella suscitada, la Sección 2a de la CGC introdujo en la PCM estos artículos:

“Artículo 213-20. Arbitraje estatutario

1. Salvo en el caso de las sociedades cotizadas, los estatutos podrán establecer que las controversias o conflictos que se susciten en la interpretación y en la aplicación de las normas en ellos contenidas, las impugnaciones de los acuerdos sociales por socios o por administradores, el ejercicio de la acción social de responsabilidad por la sociedad o por los socios contra los administradores o liquidadores o contra quienes hubieran ostentando cualquiera de estas condiciones y cualesquiera otros conflictos de naturaleza societaria se resolverán mediante arbitraje de Derecho por uno o varios árbitros, encomendándose la administración del arbitraje y la designación de los árbitros a una institución arbitral.

2. En las sociedades personalistas, la introducción en los estatutos de una cláusula de sumisión a arbitraje requerirá el consentimiento de todos los socios; en las sociedades de capital, el voto favorable de, al menos, dos tercios de los votos correspondientes a las participaciones sociales o a las acciones en que se divida el capital social”.

“Artículo 271-5. Causas específicas de separación en sociedades de capital.

1. El socio podrá separarse en las sociedades de capital cuando hubiera votado en contra de alguno de los siguientes acuerdos:

d) La introducción en los estatutos sociales de cláusulas de sumisión a arbitraje de las controversias o conflictos de naturaleza societaria.

2. Lo establecido en el apartado anterior no será de aplicación a las sociedades cotizadas”. 
Estos artículos han pasado al Anteproyecto del Gobierno, salvo el apartado 2 del 271-5, que, por causas que desconozco, se ha suprimido, dejando mutilado el artículo, con un único apartado, sub 1 , sin 2.

\section{La cláusula estatutaria de arbitraje}

a) Ubicación y contenido

El primero de estos artículos, se inserta en el Libro Segundo, De las Sociedades Mercantiles, Título I, Capítulo III. De la constitución de las sociedades mercantiles, Subsección $3^{\mathrm{a}}$, De la cláusula estatutaria de arbitraje, que comprende solo este artículo.

La ubicación sistemática indica que se refiere a todas las clases de sociedades mercantiles, con la sola y expresa excepción de las cotizadas, de las que trataremos más adelante. Se despeja así una de las dudas sembradas por el art. 11 bis.1 introducido por la reforma de 2011, que al abordar sólo el arbitraje societario en las sociedades de capital sembró la duda donde no existía.

Queda también claro que la norma del art. 213-20.1 del ACM se refiere sólo al arbitraje estatutario (“... los estatutos podrán establecer...”), y no al común, nacido de convenio arbitral extraestatutario, con lo que se despeja también la incógnita del art. 11 bis.1: "Las sociedades de capital podrán someter a arbitraje los conflictos que en ellas se planteen”. Como todas las personas jurídicas, las sociedades mercantiles pueden comprometer en árbitros la decisión de sus litigios; pero de lo que aquí se trata es de hacerlo en pacto estatutario.

Se aclara que el arbitraje estatutario ha de ser siempre de Derecho.

Finalmente, se despeja también la duda del ámbito de la norma, porque la del ACM incluye tanto la cláusula arbitral establecida en los estatutos originales (apartado 1) como la "introducción en los estatutos" por acuerdo de modificación (apartado 2). 
b) Diferencias con la Ley vigente

En cuanto a las diferencias entre el art. 11 bis LA y el 213-20 ACM, son de apreciar las siguientes:

$1^{\circ}$. El ACM detalla más la materia arbitrable ("las controversias o conflictos que se susciten en la interpretación y en la aplicación de las normas en ellos contenidas, las impugnaciones de los acuerdos sociales por socios o por administradores, el ejercicio de la acción social de responsabilidad por la sociedad o por los socios contra los administradores o liquidadores o contra quienes hubieran ostentando cualquiera de estas condiciones y cualesquiera otros conflictos de naturaleza societaria...”).

$2^{\circ}$. La norma imperativa del arbitraje administrado y con designación del árbitro o árbitros por la institución arbitral, ahora de exclusiva aplicación a la impugnación de acuerdos sociales (art. 11 bis.3 LA), se extiende a todo arbitraje societario (art. 213-20.1 ACM). Se acentúa así la objetividad de éste.

$3^{\circ}$. Se especifica que el arbitraje ha de ser de Derecho.

$4^{\circ}$. En cuanto a la "introducción" de la cláusula por vía de modificación de estatutos, se distingue ahora (art. 213-20.2) entre las sociedades personalistas y las de capital: para las primeras, se exige el régimen de unanimidad ("consentimiento de todos los socios"); para las segundas, la mayoría cualificada de $2 / 3$ de los votos que ya estableció la reforma de la Ley 11/2011.

Triunfa, pues, el principio de mayoría; pero se limita y contrapesa por la exclusión de las sociedades cotizadas y por el derecho de separación que concede el art. 275.5.1.d) al socio disidente.

\section{c) La inspiración italiana y las diferencias}

Resulta que la reforma de la Ley 11/2011 se inspiró en el Decreto Legislativo italiano de 17 de enero de 2003 (art. 34) ${ }^{16}$, pero sin las garantías que para los socios

\footnotetext{
16 Sobre el modelo italiano, V. GENNARI, F., "L'arbitrato societario", en Trattato di Diritto Commerciale e di Diritto pubblico dell'economia, dirigido por GALGANO, F., vol. 51, 2009, pp. 100108.
} 


\section{Doctrina y Jurisprudencia}

ausentes o disidentes establecía su apartado 6: el derecho de separación, introducido precisamente para evitar la inconstitucionalidad de la norma. El socio no conforme con la cláusula estatutaria arbitral tiene la salida de la separación para no verse imponer un arbitraje por la mayoría.

Se trata de una solución "garantista", pero que estimo inadecuada al supuesto de hecho. La separación es siempre una medida quirúrgica, que amputa un miembro a la sociedad y le obliga a liquidar su cuota y a reducir el capital, a no ser que se evite mediante la adquisición de aquella por los restantes socios o por la sociedad (art. 271-19 ACM), una novedad del ACM que tiende a paliar, en lo posible, ese trauma. Para el socio, también puede resultar excesivo el remedio de la separación en previsión de un eventual futuro arbitraje, cuando se encuentre cómodo en la sociedad. Pero la fórmula italiana es hábil como coartada para eludir el reproche de inconstitucionalidad: el socio puede evitar la imposición del arbitraje; si no lo hace, se presume que lo consiente, aunque no haya votado a favor del acuerdo.

La regla de la mayoría sin ese remedio resulta, pues, inconstitucional. Así lo he considerado y he señalado los medios para llegar a obtener del TC esa declaración ${ }^{17} \mathrm{La}$ interpretación del modelo italiano, como ya se había recomendado en nuestra doctrina ${ }^{18}$, evita el riesgo de inseguridad jurídica que padece nuestro Derecho vigente.

Pero la norma del ACM se diferencia todavía del modelo italiano. En primer lugar, con ventaja española, porque el régimen de mayoría en la introducción de la cláusula estatutaria sólo se contempla para las sociedades de capital, mientras que para las personalistas exige unanimidad el ACM.

V. también, PIERALLI, A.,'El nuevo arbitraje societario en Italia, análisis comparativo con España", en Anales de Justicia Alternativa, $\mathrm{n}^{\circ}$ 5, 2005, pp. 204-220, que proponía la ayuda de las normas italianas para la regulación en España de esta figura; RUFFINI, G., "Il nuovo arbitrato per le controversie societarie“, en Riv. trim. dir. e pro. civ., vol. 58, n² 2, 2004, pp. 495-532; ZUCCONI, E., "La convenzione arbitrale nella societá dopo la reforma”, en la misma Revista, vol. 57, n 3, 2005, pp. 929-972, y "Modelli arbitrali e controversia societarie", ibídem, vol. 60, nº 2, 2006, PP. 513-538.

${ }^{17}$ V. mi artículo “Quórum y mayorías...”, cit., especialmente, IV. Los remedios, pp. 815-817.

${ }^{18}$ V. mi artículo "Las aportaciones del Prof. Vicent Chuliá...”, op. et. loc. cit., p. 496. 
La segunda diferencia ya no es a favor de la norma española, porque mientras la italiana concede derechos de separación a los socios "ausentes o disidentes" (art. 34.6 del DL) el ACM solo lo concede al que "hubiere votado en contra". Parece una aplicación de la máxima “vigilantibus non dormien-tibus iura succurrunt”. Se requiere una posición activa y expresamente contraria a la introducción de la cláusula para poder ejercer el derecho de separación.

Por lo demás, no cabe duda de que el ACM he seguido ahora fielmente el modelo italiano, con las limitaciones y contrapesos que lo acompañan.

\section{La exclusión de las sociedades cotizadas}

La exclusión de las sociedades cotizadas es una limitación fundada del arbitraje estatutario. Las sociedades abiertas, de gran número de socios y accionariado "flotante" en un porcentaje considerable, se adecuan mal al arbitraje como forma de solución de conflictos sociales. De otra parte, existe en éstos un ingrediente de interés público o general que normalmente cuestiona el carácter de disponibilidad que ha de tener el conflicto arbitrable. Nuestra doctrina ya había excluido a las cotizadas del ámbito del arbitraje societario $^{19}$; en el Derecho comparado, el modelo alemán excluye de éste a todas las anónimas, no sólo a las cotizadas, y el italiano prohíbe expresamente la cláusula compromisoria no sólo a las cotizadas sino a todas aquellas que tengan su capital repartido en el público en "medida relevante" 20.

19 V. MUÑOZ PLANAS, J. Ma y MUÑOZ PAREDES, J.M a $^{\mathrm{a}}$, "El arbitraje en las sociedades profesionales", en Estudios de Derecho Mercantil en memoria del Prof. ANIBAL SÁNCHEZ ANDRÉS, Madrid, 2010, pp. 991-1001, especialmente pp. 1000 y 1001.

20 Sobre el sentido de "medida relevante”, v. BOVE, M., "L'arbitrato societario tra disciplina speciale e (nuova) disciplina di Diritto comune”, en Riv. Dir. Proc., 2008, pp. 931-954, especialmente, p. 932. 


\section{LA INSCRIPCIÓN EN EL REGISTRO MERCANTIL DEL LAUDO ESTIMATORIO DE LA IMPUGNACIÓN DE ACUERDO INSCRITO.}

El art. 214-18 del ACM dispone:

"Art. 214-18. Inscripción en el Registro mercantil de la sentencia o del laudo estimatorios.

1. La declaración judicial o arbitral que estime la impugnación de un acuerdo inscribible habrá de inscribirse en el Registro Mercantil.

2. Cuando el acuerdo impugnado estuviese inscrito en el Registro Mercantil, la sentencia o el laudo que estime la acción determinará, además, la cancelación de la inscripción, así como la de todos los asientos posteriores que resulten manifiestamente contradictorios con ella."

No hay sustanciales diferencias con el vigente art. 11 ter.

Se equiparan ahora en la norma sentencia judicial y laudo y sólo se aprecia una diferencia de matiz en la cancelación de los asientos posteriores, porque exige el ACM que se limite a los que sean "manifiestamente contradictorios" con la acción de impugnación estimada. 